\title{
Neoplastic transformation of breast epithelial cells by genotoxic stress
}

\author{
Mahendran Botlagunta' ${ }^{1}$ Paul T Winnard Jr ${ }^{1}$ and Venu Raman*1,2
}

\begin{abstract}
Background: Exposure to genotoxic stresses such as radiation and tobacco smoke can cause increased cancer incidence rate as reflected in an in depth meta-analysis of data for women and breast cancer incidence. Published reports have indicated that exposures to low dose radiation and tobacco smoke are factors that contribute to the development of breast cancer. However, there is a scarcity of information on the combinatorial effects of low dose radiation and tobacco smoke on formation and progression of breast cancer. The combination of these two genotoxic insults can induce significant damage to the genetic material of the cells resulting in neoplastic transformation.

Methods: To study the effects of low dose ionizing radiation and tobacco smoke on breast cells, MCF 10A cells were treated either with radiation (Rad - 0.1 Gray) or cigarette smoke condensate (Csc - 10 microgram $/ \mathrm{ml}$ of medium) or a combination of Rad + Csc. Following treatments, cells were analyzed for cell cycle distribution patterns and the ability to extrude the Hoechst 33342 dye. In addition, in vitro invasion and migration as well as mammosphere formation assays were performed. Finally, differential gene expression profiles were generated from the individual and combination treatment.

Results: Exposure of MCF 10A cells to the combination of radiation plus cigarette smoke condensate generated a neoplastic phenotype. The transformed phenotype promoted increased mammosphere numbers, altered cell cycle phases with a doubling of the population in $\mathrm{S}$ phase, and increased invasion and motility. Also, exclusion of Hoechst 33342 dye, a surrogate marker for increased $A B C$ transporters, was observed, which indicates a possible increase in drug resistance. In addition, changes in gene expression include the up regulation of genes encoding proteins involved in metabolic pathways and inflammation.

Conclusions: The results indicate that when normal breast cells are exposed to low dose radiation in combination with cigarette smoke condensate a phenotype is generated that exhibits traits indicative of neoplastic transformation. More importantly, this is the first study to provide a new insight into a possible etiology for breast cancer formation in individuals exposed to low dose radiation and tobacco smoke.
\end{abstract}

\section{Background}

Women who are exposed to genotoxic stresses such as radiation and tobacco smoke have increased cancer incidence rate as reflected in an in depth meta-analysis of data for cancer incidence [1-5]. In particular, flight attendants exhibit an increased risk of breast and acute myeloid leukemia cancers [1] as they are exposed to long-term doses of low-frequency electromagnetic fields [2-4]. It is well established that doses of low energy radiation can induce double stranded DNA breaks that result in altered

* Correspondence: vraman2@jhmi.edu

1 Department of Radiology, Johns Hopkins University School of Medicine, Baltimore, Maryland, USA

Full list of author information is available at the end of the article gene expression profiles in mammalian cells, which are transmitted to later generations of progeny cells [6]. This lateral transfer of aberrant genomic damage can accelerate the DNA damage rate in subsequent generations, which has been referred to as a radiation induced bystander effect $[7,8]$. Low dose ionizing radiation has also been shown to alter the intracellular production of reactive oxygen species (ROS), such as, hydrogen peroxide, superoxide anion and hydroxyl radicals [9], which induce mutations and chromosomal aberrations in cells [10]. These types of genetic alterations can promote many pathological conditions including those associated with aging and cancer $[11,12]$. Such radiation also can dysregulate the expression of stress related proteins and 
oncoproteins. For example, a number of cellular proteins such as transcription factors (c-Jun, c-fos, IL1, egr-1), cell cycle control (p53, cyclin A and B), and DNA metabolizing proteins (PCNA, $\beta$ polymerase, PARP) have been shown to be elevated following low dose irradiation [1317]. Hence, it can be inferred that long term exposure to low dose ionizing radiation can initiate the carcinogenesis process [18].

Besides low dose radiation, there is also a growing body of evidence supporting the hypothesis that exposure to tobacco smoke is a contributing factor in neoplastic transformation of breast cells [5]. Environmental tobacco smoke has been shown to contain high amounts of polycyclic aromatic hydrocarbons (PAHs) many of which have been shown to be potent carcinogens [19-21]. In a rat model, exposure to PAHs rapidly induced palpable mammary tumors [22]. Histological analysis revealed a high incidence of adenocarcinoma indicating the potent carcinogenic property of PAHs. In addition, exposure of human mammary epithelial cells (HMECs) and breast cancer cell lines to an activated PAH: racemic anti-3,4dihydroxy-1,2-epoxy-1,2,3,4 tetrahydrobenzo phenanthrene (BPDE), found in active and passive cigarette smoke, exhibited altered cell cycle progression, decreased BRCA-1 expression, an increased a spectrum of p53 mutations [23-26] and neoplastic transformation [5]. Additionally, BRCA1 and BRCA2 mutational carriers, who are also smokers, are at an increased risk of getting breast cancer [27]. In contrary, there is evidence to indicate that active smoke does not increase risk of breast cancer in a cohort Japanese women [28].

The combined effect of long-term human exposure to cigarette smoke in combination with ionizing radiation is not known. Thus, the purpose of this research was to determine the combined effects of radiation and cigarette smoke on the ontogeny of breast cancer formation and progression. Towards this goal, we have found that exposure of non-tumorigenic immortalized MCF 10A breast cells to low dose radiation and cigarette smoke condensate promoted a transformed phenotype. These results provide a new insight into a possible etiology for breast cancer formation in populations such as medical staff, aircrews, nuclear test participants and nuclear industry workers that are exposed to low dose radiation and simultaneously may have the likelihood to be exposed to active and second hand cigarette smoke.

\section{Methods}

\section{Cell culture and exposure to radiation and cigarette smoke} condensate

MCF 10A cells (ATCC, Rockville, MD) were irradiated at $0.67 \mathrm{cGy} / \mathrm{min}$ to the desired dose (0.1 Gy) using a $\gamma$-cell $40{ }^{137}$ Cesium irradiator (Atomic Energy of Canada). A 40 $\mathrm{mg} / \mathrm{ml}$ stock solution of cigarette smoke condensate
(Murthy Pharmaceuticals, USA) was prepared in DMSO and diluted with culture medium to a final concentration of $10 \mathrm{mg} / \mathrm{ml}$. Exponentially growing cells were first irradiated and then exposed to Csc $(10 \mu \mathrm{g} / \mathrm{ml})$ for $72 \mathrm{hr}$ [29].

\section{Flow cytometry and immunoblot analysis}

Determination of DNA content by flow cytometry was performed as previously described [30]. Briefly, $2 \times 10^{6}$ MCF 10A cells were incubated for $72 \mathrm{hr}$ following individual and combined treatments. Fixed cells were incubated with a staining solution containing $0.56 \%$ NP-40, $3.7 \%$ formaldehyde, and $0.01 \mathrm{mg} / \mathrm{ml}$ Hoechst 33258 in phosphate-citrate buffered ( $\mathrm{pH}$ 7.2) solution. DNA content was analyzed by flow cytometry instrumentation (BD Biosciences, San Jose, CA).

For immunoblot experiments, $20 \mu \mathrm{g}$ of total cellular protein was subjected to SDS-PAGE. Membranes were probed with the primary antibodies indicated in the figure legend.

\section{Invasion and wound healing}

Matrigel (100 $\mu \mathrm{l} ; 7-8 \mathrm{mg} / \mathrm{ml})$ in serum-free medium was added to each well of a Transwell Corning Costar plate (Costar, Acton, MA, USA) and dried overnight in a tissue culture hood. The following day, $2.5 \times 10^{4}$ cells in serumfree medium were pipetted onto the Matrigel and complete medium was added to the bottom trough. Following incubation, the transmembrane filter was stained with crystal violet and the number of cells counted.

For wound healing, a small area was cleared along a diameter of the $10 \mathrm{~cm}$ dishes of confluent monolayers of MCF 10A and MCF 10A treated cells with a sterile pipette tip. Cell migration was measured and photographed from the wound/scratch edge every $8 \mathrm{hr}$.

\section{Hoechst 33342 dye exclusion assay}

Following treatments, cells were incubated in $0.01 \mathrm{mg} / \mathrm{ml}$ of Hoechst 33242 dye for 45 minutes and then washed and incubated for a further 45 minutes and photographed using the Nikon 80i fluorescent microscope. Fluorescence intensity per cell (blue channel) was analyzed using image J software ( $n=4$ in each case).

\section{Affymetrix analysis}

RNA was extracted using the Qiagen mRNA extraction kit. The RNA samples were analyzed with Affymetrix GeneChip Human 1332.0 Arrays. The quality of the microarray experiments was assessed with affyPLM and Affy, found at Bioconductor http://www.bioconductor.org. All computation was performed under $R$ environment http://www.r-project.org. The Affy software was used to estimate the gene expression signals and evaluated using the Robust Multi-array Average [31]. Data normalization was performed using a Bayes method at Bioconductor, which includes log normal modeling. 
EBarrays was used to estimate the posterior probabilities of the differential expression of genes between the control and treated sample [32,33]. This data has been deposited with Gene Expression Omnibus (GEO-accession number GSE21066).

\section{Generation of mammospheres}

Single cell suspensions (total 5000 cells in $2 \mathrm{ml}$ ) in Dulbecco's modified Eagle's medium/F-12 containing $5 \mathrm{mg} /$ $\mathrm{mL}$ insulin, $0.5 \mathrm{mg} / \mathrm{mL}$ hydrocortisone, 2\% B27 (Invitrogen Ltd., Paisley, Scotland), and $20 \mathrm{ng} / \mathrm{mL}$ epidermal growth factor were seeded into ultra-low attachment plates (Corning, Lowell, MA) and incubated for 7-10 days in presence of $20 \% \mathrm{O}_{2}$ and $5 \% \mathrm{CO}_{2}$ at $37^{\circ} \mathrm{C}$. Subsequently, the number of mammospheres formed were counted using a microscope.

\section{Results}

Effects of low dose ionizing radiation and cigarette smoke condensate on MCF $10 \mathrm{~A}$ cells

The effect of low dose ionizing radiation and cigarette smoke condensate was tested using MCF 10A normal immortalized breast cells. Following treatments, we observed differences between the morphological appearances of the differently treated cultures. Single treatment regimes generated consistent changes in cellular morphologies relative to the untreated controls (Figure 1A). Thus, irradiation or Csc treatment resulted in populations of cells with a rounded or slightly elongated morphology (Figure 1A top right and lower left panels). In contrast, combined treatment (Rad + Csc) of MCF 10A cells generated a phenotype that was somewhat fibroblast-like (Figure 1A lower right panel), which grew with fewer cell to cell contacts and was less cuboidal than the parental cells. Flow cytometry analyses were performed to evaluate whether the latter phenotypic changes could be associated with a change in cell growth rate or cell cycle frequency and hence a change in proliferation rate. As shown in Figure 1B, irradiation (0.1 Gray) increased the percentage of cells found in G2/M from the 3.7\% found in the untreated cells to $39.2 \%$ while Csc treatment increased the percentage of cells in G0/G1 from 49\% found in untreated cells to $75.4 \%$. Thus, irradiation did not cause G1 arrest for MCF 10A cells while Csc treatment caused G1 arrest. However, treatment of MCF 10A cells with a combination of radiation plus Csc resulted in $42.9 \%$ of the cells being in S phase, which is roughly double that of the untreated cells and provides an indication that the combined treatment increased the percentage of proliferating cells (Figure 1B). Subsequently, immunoblot analyses were performed to investigate whether the cell cycle changes mediated by genotoxic stress could be correlated to the expression of cell cycle regulatory proteins. As indicated in Figure 1C, p53 protein levels were slightly increased following low dose irradiation, which was matched to an increase in the levels of its downstream target p21. In contrast to Rad, Csc or a combination of radiation plus Csc treatment resulted in a down regulation of p53 and p21 levels (Figure 1C). This indicates that
A)


MCF 10A + Rad

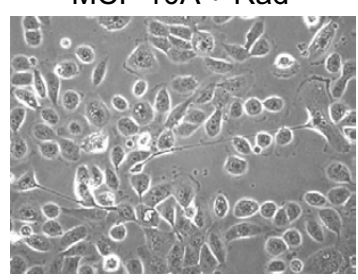

MCF $10 A+\operatorname{Rad}+\mathrm{Csc}$

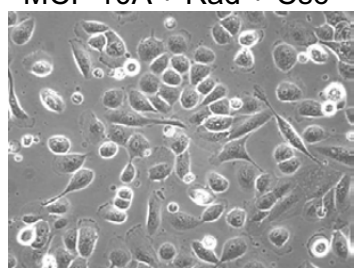

B)

\begin{tabular}{lcccc}
\hline & $\begin{array}{c}\text { MCF 10A } \\
\text { Untreated }\end{array}$ & $\begin{array}{c}\text { MCF 10A } \\
\text { Rad }\end{array}$ & $\begin{array}{c}\text { MCF 10A } \\
\text { Csc }\end{array}$ & $\begin{array}{c}\text { MCF 10A } \\
\text { Rad + Csc }\end{array}$ \\
\hline G0/G1 & 49.00 & 2.03 & 75.39 & 13.11 \\
S & 23.00 & 28.62 & 0.89 & 42.92 \\
G2/M & 3.70 & 32.91 & 10.64 & 14.39 \\
\hline
\end{tabular}

C)

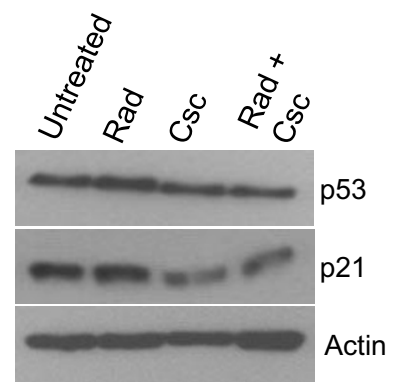

Figure 1 Phenotypic characterization and cell cycle analyses of MCF 10A cells treated with radiation and cigarette smoke condensate. Panel A - Photomicrographs of MCF 10A-Rad + Csc treated cells (elongated) as compared to the parental MCF 10A cells (cuboidal). Panel B - Shows the percentage of cells distributed at the different phases of the cell cycle. Panel C - Immunoblot analyses of cell extracts from the control and treated MCF 10A cells. Primary antibodies were against p53 (Santa Cruz) and p21 (Cell Signaling). $\beta$-actin (Sigma) was scored for loading control. 
$\mathrm{Rad}+$ Csc can alter the levels of regulatory molecules to dysregulate phases of the cell cycle.

Migration and invasive capabilities of treated MCF $10 \mathrm{~A}$ cells Increased cell motility and invasion are characteristics of a neoplastic transformation. To test whether the genotoxic stresses used in our experimental setting could increase the migration of MCF $10 \mathrm{~A}$ cells, we used a scratch/wound assay. As shown in Figure 2A, MCF 10A cells treated with Rad as well as Rad + Csc were able to migrate into the cleared area within $24 \mathrm{hr}$ of incubation. On the other hand, untreated and Csc treated MCF 10A cells showed little migration into the cleared region during this time period. We next investigated the effect of radiation and $\mathrm{Csc}$ on cell invasion in a modified Boyden chamber assay. As depicted in Figure 2B, MCF 10 A cells treated with Csc lack the ability to invade whereas Rad or the combination Rad + Csc cells were extremely invasive (four fold increase) as compared to the untreated and Csc treated MCF 10A cells. Taken together these data indi- cate that the Rad as well as Rad + Csc treated cells acquired genetic/biochemical alterations that increased the cells ability to migrate and invade, i.e., a possible increase in dissemination or metastatic potential.

\section{MCF 10A treated cells exhibit increase efflux of Hoechst 33342 dye}

A distinct characteristic of a metastatic phenotype is generally increased drug resistant properties. Some of the pathways that promote drug resistance are elevated expression of ATP-binding cassette $(\mathrm{ABC})$ glycoprotein transporters at the cell surface [34]. The elevated expression of these transporters can exclude vital dyes such as Hoechst 33342 analogues to chemotherapeutic drugs, thus promoting multi-drug resistance. As MCF 10A cells treated with $\mathrm{Rad}+\mathrm{Csc}$ induced a transformed phenotype, we evaluated the ability of these cells to extrude the Hoechst 33342 dye, a surrogate marker for drug uptake. As seen in Figure 2C \&2D, cells treated with both Rad + Csc retained less dye as compared to the untreated MCF
A)

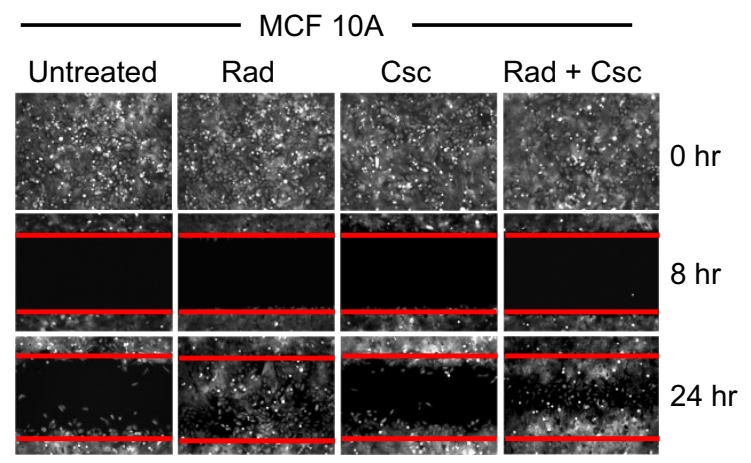

C)
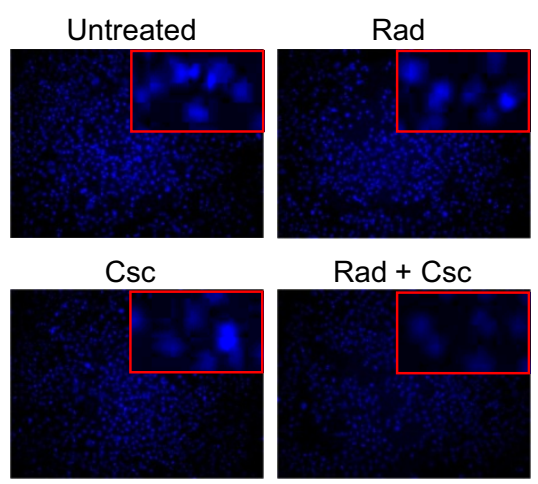

B)



Figure 2 Invasion and wound healing assays of the treated MCF 10A cells. Panel A - In vitro wound healing assay. A filling of the cleared area, as demarcated by the horizontal red lines, was followed microscopically at 20x magnification. Panel B - Bar graph quantifying invasion of treated and untreated MCF 10A cells using Boyden chambers (means, $n=2$ ). Panel C - Efflux of Hoechst 33342 in MCF 10A treated cells. Inset shows 40x magnification of representative cells. Panel D - Bar graph showing quantification of the fluorescence intensity per cell in the blue channel. 
10A cells. This indicates that the combination treatment in MCF 10A cells can induce a drug resistant phenotype.

\section{Changes in gene expression profile and mammosphere formation following genotoxic stress}

In an effort to determine which genes might be contributing to the increased cell invasion and migration capabilities of $\mathrm{Rad}$ or $\mathrm{Rad}+\mathrm{Csc}$ treated MCF 10A cells, we performed expression analyses using the Affymetrix platform. To identify differentially expressed gene sets following treatment, we compared the individual (Rad or Csc) treatment data sets with the combined treatment $(\mathrm{Rad}+\mathrm{Csc})$ data set using a Venn diagram (Figure 3A). The Venn diagram indicates that 53 genes differentially expressed in the combination treated cells compared to untreated cells. Among these, 18 genes (12 up regulated and 6 down regulated) have been reported as participating in cellular pathways of cancer (Figure 3B). Included in this group were genes involved in tissue remodeling, metabolism and cell adhesion molecules. One cell adhesion molecule identified was CD44, which has been directly correlated to human breast cancer grade [35]. Moreover, a high CD44 low CD24 expression profile in breast cancer cell lines has been associated with a putative breast cancer initiating cell phenotype [36]. In order to validate the microarray data, we estimated the CD44 levels in treated versus untreated cell lines. The expression level of CD44 was up regulated 2 fold in the combined treatment as compared to the untreated and Rad treated (Figure 3C). Recently, cells exhibiting a high CD44 low CD24 expression profile have been shown to form mammospheres in culture conditions, which were resistant to chemotherapeutic regimes [37]. Therefore, we investigated the effect of genotoxic stress on MCF 10A cells to form mammospheres in vitro. Figure 4A shows representative mammosphere images under different genotoxic stress. The combined treated cells formed the most number of mammospheres as compared to individual treatments (Figure 4B). Thus, the Affymetrix data indicates that the combined treatment can initiate gene expression patterns that are associated with known cancers. That along with enhanced mammosphere formation

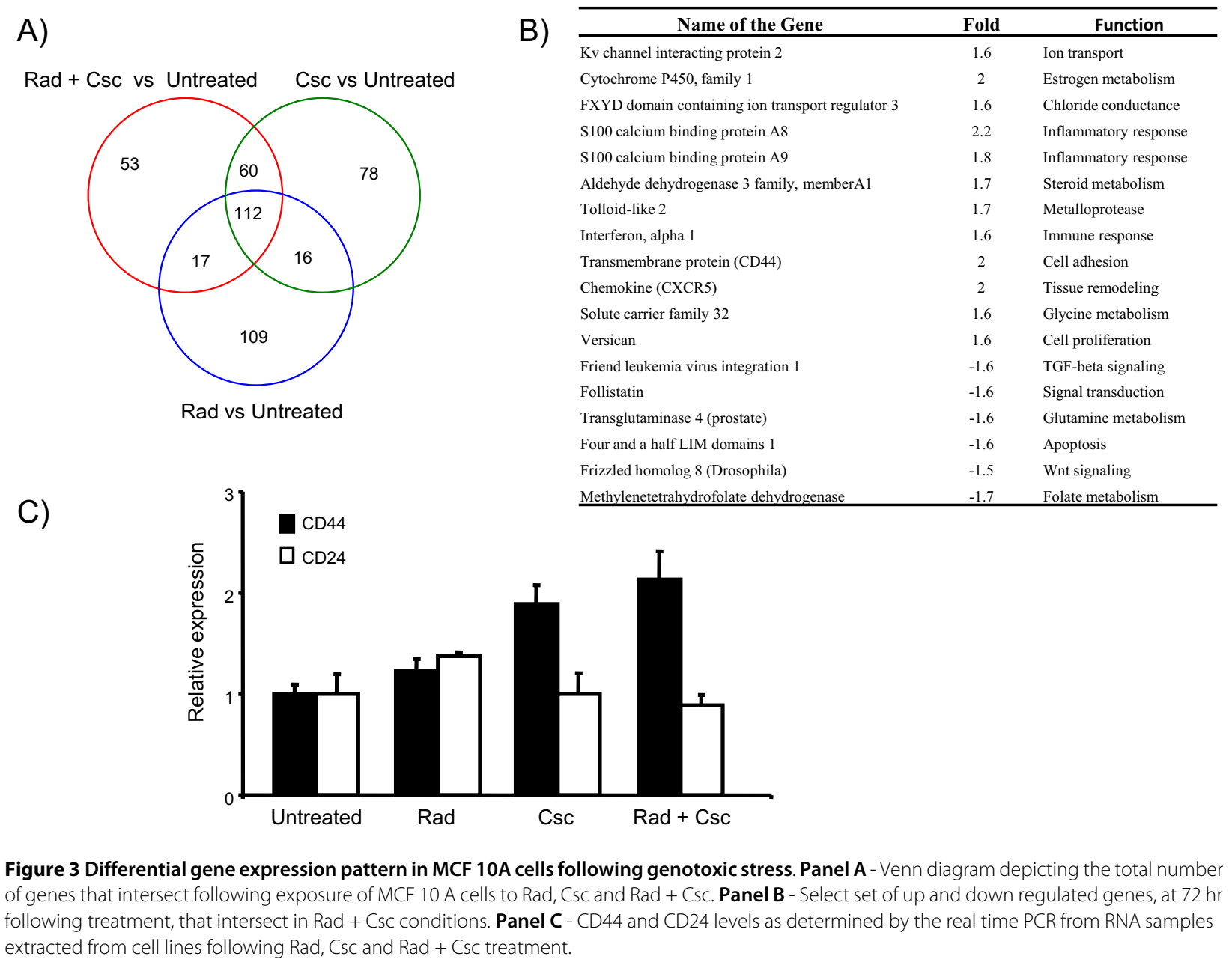


A)

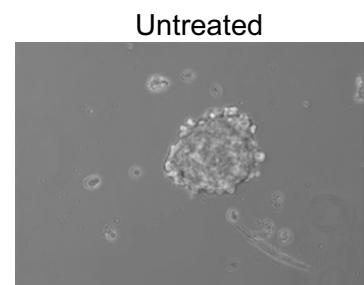

Csc



$\operatorname{Rad}$

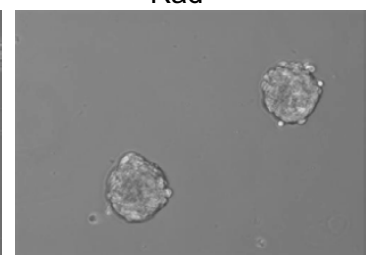

$\mathrm{Rad}+\mathrm{Csc}$

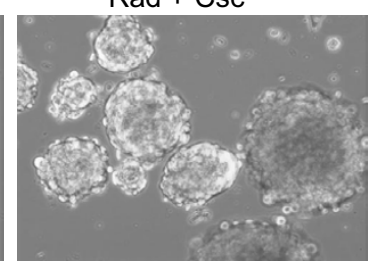

B)

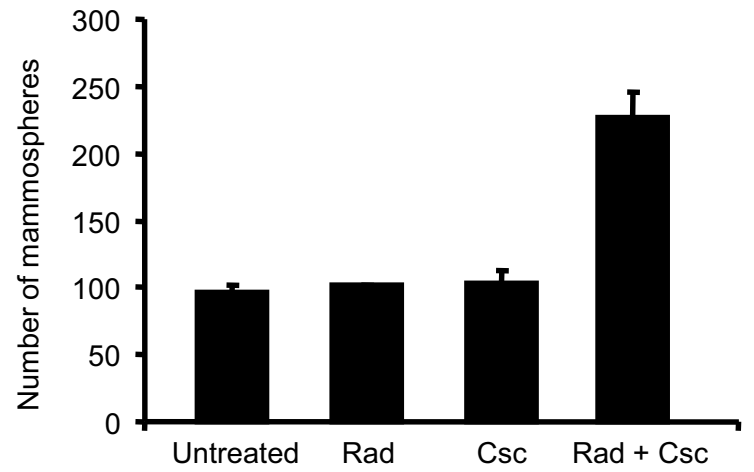

Figure 4 Mammosphere formation of MCF 10A cells treated with radiation and cigarette smoke condensate. Panel A - Photomicrographs of the mammospheres following treatment with Rad, Csc and Rad + Csc. Panel B - Shows the total number of mammospheres following exposure to Rad, Csc and Rad + Csc. The counts represented are averages from two independent experiments.

strengthens our suggestion that further experiments will indicate that the altered gene profiles are consistent representations of known cancer cell phenotypes.

\section{Discussion}

Long-term exposure to low dose radiation at levels that can damage normal cell functions and propagate dsyregulated molecular programs can generate diseased tissue. For example, aircrews, medical staff and workers in the nuclear energy industry are often exposed to low dose radiation as well as cigarette smoke and the combined effect of these two environmental stresses likely identifies these as a few of the populations that have an increased risk of developing cancer. As low dose radiation and cigarette smoke exposure may very well alter the breast tissue biochemistry, physiology, and morphology, it is essential to determine if the combined effects of such exposures induces genetic/biochemical alterations that can trigger breast tumor formation. Such considerations led us to study the action of the combined environmental genotoxic stresses of low dose radiation and cigarette smoke condensate on immortalized non-tumorigenic breast epithelial cells, MCF 10A. The finding that exposing cells to both Rad + Csc generated cells that exhibited a fibroblastic phenotype, which is different from the normal cuboidal shaped MCF 10A cells, is a clear indication that fundamental genetic alterations occurred during treatment. The low dose irradiation used in this study induced cell cycle arrest (G2/M), which is in agreement with this well known effect occurring in cells exposed to radiation [38]. Although, we observed only marginal increases in p53 and p21, these changes nevertheless support the known function of these proteins in this check point process [39]. However, Csc and combined treated cells reversed or abrogated the check point response to ionizing radiation and caused a shift in cell cycle to G0/G1 and $\mathrm{S}$ phase respectively with concomitant decreases in p53 and p21. The alterations in the cell cycle distribution pattern following combined treatment indicates that a combination of genotoxic exposures is more detrimental with respect to the generation of a proliferating phenotype then either single exposure under the conditions used here.

Tumorigenesis is a complex process and it involves intricate biological mechanisms such as invasion and motility that are essential attributes of metastasis [40]. We observed that Rad or Rad + Csc doubled the percentage of cells that invaded the Matrigel. We have further demonstrated that exposure of MCF 10A cells to low dose radiation followed by Csc altered the transcription profiles of a number of genes that fell into two broad categories: (1) those with common responses across individual treatments and (2) those with differential responses associated with combined treatment. Our study is the first genome-wide analysis of transcript profiles associated with concomitant radiation and cigarette smoke condensate exposures. The major changes associated with the differential response can be categorized as those cellular properties associated with tissue remodeling, metabolism, and altered cell membrane protein levels, while a more ambiguous outcome was observed for genes involved in inflammation and signaling events. Our findings of increased transcript levels in a large number of metabolic genes appear to indicate that metabolism is an important component of stress response mechanisms after exposure to radiation or Csc. An increase in Cytochrome P450 observed in Rad + Csc treated cells may metabolically activate the carcinogens present in ciga- 
rette smoke within the breast environment to promote carcinogenesis. Furthermore, cell membrane proteins have been previously reported to be elevated after low dose radiation exposures [41]. The significant changes in the expression level of CD44 and mammosphere number induced by Rad + Csc supports the generation of radioresistant phenotype as compared to individual treated fraction [37].

Although a direct correlation of results obtained on cultured human cells to the human situation requires additional research, we envisage that the results of the present study will help initiate further studies on the affects of long term human exposure to low dose radiation and tobacco smoke in the pathogenesis of breast cancer.

\section{Conclusions}

In conclusion, we have demonstrated that short term exposure of normal breast cells to low doses of ionizing radiation and the potent carcinogens in tobacco smoke condensate can induce genetic and phenotypic changes that reflect those of known cancer cell types. Given the limitations of these in vitro studies and the complexities of translating these findings to real life responses to such environmental mutagens and carcinogens is a strong indication that further investigation will be required to conclusively demonstrate the risk of getting breast cancer following exposure to low dose radiation and cigarette smoke. Still this is the first study to demonstrate the effects of low dose ionizing radiation in combination with exposures to tobacco smoke carcinogens that can result in a possible initiation of cellular processes that give rise to breast cancer cells.

\section{Abbreviations}

Rad: radiation; Csc: cigarette smoke condensate; ABC: ATP-binding cassette; ROS: reactive oxygen species.

\section{Competing interests}

The authors declare that they have no competing interests.

\section{Authors' contribution}

MB collected and analyzed the data and drafted the manuscript. PW helped in the data analysis and manuscript writing. VR conceived the study and participated in data analysis, interpretation and manuscript writing. All authors have read and approved the final manuscript.

\section{Acknowledgements}

This work was supported by a grant from the Flight Attendant Medical Research Institute to Venu Raman.

\section{Author Details}

1Department of Radiology, Johns Hopkins University School of Medicine, Baltimore, Maryland, USA and 2Department of Oncology, Johns Hopkins University School of Medicine, Baltimore, Maryland, USA

Received: 31 August 2009 Accepted: 30 June 2010

Published: 30 June 2010
References

1. Ballard T, Lagorio S, De Angelis G, Verdecchia A: Cancer incidence and mortality among flight personnel: a meta-analysis. Aviat Space Environ Med 2000, 71(3):216-224.

2. Nicholas JS, Lackland DT, Dosemeci M, Mohr LC Jr, Dunbar JB, Grosche B, Hoel DG: Mortality among US commercial pilots and navigators. J Occup Environ Med 1998, 40(11):980-985.

3. Lim MK: Exposure of airline pilots and cabin crew to cosmic radiation during flight--what's the fuss? Ann Acad Med Singapore 2001 30(5):494-498

4. Kojo K, Helminen M, Leuthold G, Aspholm R, Auvinen A: Estimating the cosmic radiation dose for a cabin crew with flight timetables. J Occup Environ Med 2007, 49(5):540-545.

5. Botlagunta M, Vesuna F, Mironchik Y, Raman A, Lisok A, Winnard P Jr Mukadam S, Van Diest $P$, Chen JH, Farabaugh $P$, et al:: Oncogenic role of DDX3 in breast cancer biogenesis. Oncogene 2008, 27(28):3912-3922.

6. Goodhead DT: Initial events in the cellular effects of ionizing radiations: clustered damage in DNA. Int J Radiat Biol 1994, 65(1):7-17.

7. Little JB: Genomic instability and bystander effects: a historical perspective. Oncogene 2003, 22(45):6978-6987.

8. Mothersill C, Seymour C: Radiation-induced bystander and other nontargeted effects: novel intervention points in cancer therapy? Curr Cancer Drug Targets 2006, 6(5):447-454

9. Narayanan PK, Goodwin EH, Lehnert BE: Alpha particles initiate biological production of superoxide anions and hydrogen peroxide in human cells. Cancer Res 1997, 57(18):3963-3971.

10. Brooks AL: Paradigm shifts in radiation biology: their impact on intervention for radiation-induced disease. Radiat Res 2005, 164(4 Pt 2):454-461.

11. Finkel T, Holbrook NJ: Oxidants, oxidative stress and the biology of ageing. Nature 2000, 408(6809):239-247.

12. Balkwill F, Mantovani A: Inflammation and cancer: back to Virchow? Lancet 2001, 357(9255):539-545.

13. FitzGerald TJ, Santucci MA, Das I, Kase K, Pierce JH, Greenberger JS: The vabl, c-fms, or v-myc oncogene induces gamma radiation resistance of hematopoietic progenitor cell line $32 \mathrm{~d} \mathrm{cl} 3$ at clinical low dose rate. Int J Radiat Oncol Biol Phys 1991, 21(5):1203-1210.

14. Miller AC, Gafner J, Clark EP, Samid D: Differences in radiation-induced micronuclei yields of human cells: influence of ras gene expression and protein localization. Int J Radiat Biol 1993, 64(5):547-554.

15. Chang EH, Pirollo KF, Zou ZQ, Cheung HY, Lawler EL, Garner R, White E, Bernstein WB, Fraumeni JW Jr, Blattner WA: Oncogenes in radioresistant, noncancerous skin fibroblasts from a cancer-prone family. Science 1987, 237(4818):1036-1039.

16. Kasid UN, Weichselbaum RR, Brennan T, Mark GE, Dritschilo A Sensitivities of NIH/3T3-derived clonal cell lines to ionizing radiation: significance for gene transfer studies. Cancer Res 1989, 49(12):3396-3400

17. Hanna E, Shrieve DC, Ratanatharathorn V, Xia X, Breau R, Suen J, Li S: A novel alternative approach for prediction of radiation response of squamous cell carcinoma of head and neck. Cancer Res 2001, 61(6):2376-2380.

18. Barcellos-Hoff MH, Park C, Wright EG: Radiation and the microenvironment - tumorigenesis and therapy. Nat Rev Cancer 2005 5(11):867-875

19. Egan KM, Stampfer MJ, Hunter D, Hankinson S, Rosner BA, Holmes M, Willett WC, Colditz GA: Active and passive smoking in breast cancer: prospective results from the Nurses' Health Study. Epidemiology 2002, 13(2):138-145

20. Pirkle JL, Flegal KM, Bernert JT, Brody DJ, Etzel RA, Maurer KR: Exposure of the US population to environmental tobacco smoke: the Third National Health and Nutrition Examination Survey, 1988 to 1991. Jama 1996, 275(16):1233-1240.

21. Reynolds P, Hurley S, Goldberg DE, Anton-Culver H, Bernstein L, Deapen D, Horn-Ross PL, Peel D, Pinder R, Ross RK, et al: Active smoking, household passive smoking, and breast cancer: evidence from the California Teachers Study. J Nat/ Cancer Inst 2004, 96(1):29-37.

22. Hecht SS: Tobacco smoke carcinogens and breast cancer. Environ Mol Mutagen 2002, 39(2-3):119-126.

23. Wang A, Gu J, Judson-Kremer K, Powell KL, Mistry H, Simhambhatla P, Aldaz CM, Gaddis S, MacLeod MC: Response of human mammary 
epithelial cells to DNA damage induced by BPDE: involvement of novel regulatory pathways. Carcinogenesis 2003, 24(2):225-234.

24. Burdick AD, Ivnitski-Steele ID, Lauer FT, Burchiel SW: PYK2 mediates antiapoptotic AKT signaling in response to benzo[a]pyrene diol epoxide in mammary epithelial cells. Carcinogenesis 2006, 27(11):2331-2340.

25. Jeffy BD, Chirnomas RB, Chen EJ, Gudas JM, Romagnolo DF: Activation of the aromatic hydrocarbon receptor pathway is not sufficient for transcriptional repression of BRCA-1: requirements for metabolism of benzo[a]pyrene to $7 \mathrm{r}, 8 \mathrm{t}$-dihydroxy-9t,10-epoxy-7,8,9,10tetrahydrobenzo[a]pyrene. Cancer Res 2002, 62(1):113-121.

26. Pfeifer GP, Denissenko MF, Olivier M, Tretyakova N, Hecht SS, Hainaut P: Tobacco smoke carcinogens, DNA damage and p53 mutations in smoking-associated cancers. Oncogene 2002, 21(48):7435-7451.

27. Smoking and risk of breast cancer in carriers of mutations in BRCA1 or BRCA2 aged less than 50 years. Breast Cancer Res Treat 2008, 109(1):67-75.

28. Lin Y, Kikuchi S, Tamakoshi K, Wakai K, Kondo T, Niwa Y, Yatsuya H, Nishio $\mathrm{K}$, Suzuki S, Tokudome S, et al: Active smoking, passive smoking, and breast cancer risk: findings from the Japan Collaborative Cohort Study for Evaluation of Cancer Risk. J Epidemiol 2008, 18(2):77-83.

29. Kundu CN, Balusu R, Jaiswal AS, Gairola CG, Narayan S: Cigarette smoke condensate-induced level of adenomatous polyposis coli blocks longpatch base excision repair in breast epithelial cells. Oncogene 2007, 26(10):1428-1438.

30. Gajewski E, Gaur S, Akman SA, Matsumoto L, van Balgooy JN, Doroshow $\mathrm{JH}$ : Oxidative DNA base damage in MCF-10A breast epithelial cells at clinically achievable concentrations of doxorubicin. Biochem Pharmacol 2007, 73(12):1947-1956

31. Irizarry RA, Hobbs B, Collin F, Beazer-Barclay YD, Antonellis KJ, Scherf U, Speed TP: Exploration, normalization, and summaries of high density oligonucleotide array probe level data. Biostatistics 2003, 4(2):249-264

32. Newton MA, Kendziorski CM, Richmond CS, Blattner FR, Tsui KW: On differential variability of expression ratios: improving statistical inference about gene expression changes from microarray data. J Comput Biol 2001, 8(1):37-52.

33. Kendziorski CM, Newton MA, Lan H, Gould MN: On parametric empirical Bayes methods for comparing multiple groups using replicated gene expression profiles. Stat Med 2003, 22(24):3899-3914.

34. Hadnagy A, Gaboury L, Beaulieu R, Balicki D: SP analysis may be used to identify cancer stem cell populations. Exp Cell Res 2006, 312(19):3701-3710.

35. Diaz LK, Zhou X, Wright ET, Cristofanilli M, Smith T, Yang Y, Sneige N, Sahin A, Gilcrease MZ: CD44 expression is associated with increased survival in node-negative invasive breast carcinoma. Clin Cancer Res 2005, 11(9):3309-3314.

36. Al-Hajj M, Wicha MS, Benito-Hernandez A, Morrison SJ, Clarke MF: Prospective identification of tumorigenic breast cancer cells. Proc Natl Acad Sci USA 2003, 100(7):3983-3988.

37. Li X, Lewis MT, Huang J, Gutierrez C, Osborne CK, Wu MF, Hilsenbeck SG, Pavlick A, Zhang X, Chamness GC, et al.: Intrinsic resistance of tumorigenic breast cancer cells to chemotherapy. J Natl Cancer Inst 2008, 100(9):672-679.

38. Janicke RU, Engels IH, Dunkern T, Kaina B, Schulze-Osthoff K, Porter AG: lonizing radiation but not anticancer drugs causes cell cycle arrest and failure to activate the mitochondrial death pathway in MCF-7 breast carcinoma cells. Oncogene 2001, 20(36):5043-5053.

39. Hofseth $\mathrm{L}$ : The adaptive imbalance to genotoxic stress: genome guardians rear their ugly heads. Carcinogenesis 2004, 25(10):1787-1793.

40. Winnard PT Jr, Pathak AP, Dhara S, Cho SY, Raman V, Pomper MG: Molecular imaging of metastatic potential. J Nucl Med 2008, 49(Suppl 2):96S-112S

41. Coleman MA, Yin E, Peterson LE, Nelson D, Sorensen K, Tucker JD, Wyrobek AJ: Low-dose irradiation alters the transcript profiles of human lymphoblastoid cells including genes associated with cytogenetic radioadaptive response. Radiat Res 2005, 164(4 Pt 1):369-382

Pre-publication history

The pre-publication history for this paper can be accessed here: http://www.biomedcentral.com/1471-2407/10/343/prepub doi: 10.1186/1471-2407-10-343

Cite this article as: Botlagunta et al., Neoplastic transformation of breast epithelial cells by genotoxic stress BMC Cancer 2010, 10:343

\section{Submit your next manuscript to BioMed Centra and take full advantage of:}

- Convenient online submission

- Thorough peer review

- No space constraints or color figure charges

- Immediate publication on acceptance

- Inclusion in PubMed, CAS, Scopus and Google Scholar

- Research which is freely available for redistribution

Submit your manuscript at www.biomedcentral.com/submit
C BioMed Central 